\title{
Identification of Degradant Impurity in Gefitinib by Using Validated RRLC Method
}

\author{
Madireddy Venkataramanna ${ }^{1,3}$, Indukuri Venkata Somaraju ${ }^{2,3}$, Kondra Sudhakar Babu ${ }^{3}$ \\ ${ }^{1}$ Hetero Labs Ltd., Hetero House, Santhnagar, India \\ ${ }^{2}$ Invagen Pharmaceuticals INC, Hauppauge, New York, USA \\ ${ }^{3}$ Department of Chemistry, Sri Krishna Devaraya University, Anantapur, India \\ E-mail: \{venky75, ivsraju\}@gmail.com \\ Received August 4, 2010; revised September 30, 2010; accepted October 5, 2010
}

\begin{abstract}
Degradation pathway for gefitinib is established as per ICH recommendations by validated and stability indicating reverse phase liquid chromatographic method. Gefitinib is subjected to stress conditions of acid, base, oxidation, thermal and photolysis. Significant degradation is observed in acid and base stress conditions. Two impurities are studied among which one impurity is found prominent degradant. The stress samples are assayed against a qualified reference standard and the mass balance is found close to $99.5 \%$. Efficient chromatographic separation is achieved on a Agilent make XDB-C18, $50 \times 4.6 \mathrm{~mm}$ with $1.8 \mu \mathrm{m}$ particles stationary phase with simple mobile phase combination delivered in gradient mode and quantification is carried at $250 \mathrm{~nm}$ at a flow rate of $0.5 \mathrm{~mL} \cdot \mathrm{min}^{-1}$. In the developed RPLC method the resolution between gefitinib and the potential impurities is found to be greater than 5.0. Regression analysis shows an rvalue (correlation coefficient) of greater than 0.998 for gefitinib and the two potential impurities. This method is capable to detect the impurities of gefitinib at a level of $0.01 \%$ with respect to test concentration of $0.5 \mathrm{mg} \cdot \mathrm{mL}^{-1}$ for a $4-\mu \mathrm{L}$ injection volume. The developed RRLC method is validated with respect to specificity, linearity $\&$ range, accuracy, precision and robustness for impurities determination and assay determination.
\end{abstract}

Keywords: Column Liquid Chromatography, Gefitinib, Forced Degradation, Validation, Stability Indicating

\section{Introduction}

Gefitinib: N-(3-chloro-4-fluoro-phenyl)-7-methoxy-6-(3morpholin-4-yl propoxy) quinazolin-4-amine (Figure 1) is an anticancer. The generic name of gefitinib is iressa; gefitinib is a drug that is used to treat several types of cancer. It works by preventing lung cancer cells from growing and multiplying. Gefitinib is used alone (monotherapy) for the treatment of patients with a certain type of lung cancer (non-small cell lung cancer or NSCLC) that has not responded to chemotherapy [1-4]. Literature survey reveals an analytical method is reported for the determination of gefitinib in human plasma, mouse plasma and tissues using high performance liquid chromatography coupled to tandem mass spectrometry and a method is reported for estimation of gefitinib in tablet dosage forms by RP-HPLC [5-6]. As far as we are aware there is no stability-indicating rapid resolution liquid chromatography method for determination of related substances and assay determination of gefitinib. In this paper we describe validation of related substances and assay method for accurate quantification of two potential process impurities in gefitinib samples as per ICH recommendations. Intensive stress studies are carried out on gefitinib; accordingly a stability-indicating method is developed, which could separate various degradants.

The present active pharmaceutical ingredient (API) stability test guideline Q1A (R2) issued by international conference on harmonization (ICH) [7] suggests that stress studies should be carried out on active pharmaceutical ingredient (API) to establish its inherent stability characteristics, leading to separation of degradation products and hence supporting the suitability of the proposed analytical procedures. It also requires that analytical test procedures for stability samples should be stability indicating and they should be fully validated. Accordingly, the aim of present study is to establish degradation pathway of gefitinib through stress studies under a 
<smiles>COc1cc2ncnc(Nc3ccc(F)c(Cl)c3)c2cc1OCCCN1CCOCC1</smiles>

Gefitinib: N-(3-chloro-4-fluoro-phenyl)-7-methoxy-6-(3-morpholin-4ylpropoxy) quinazolin-4-amine.

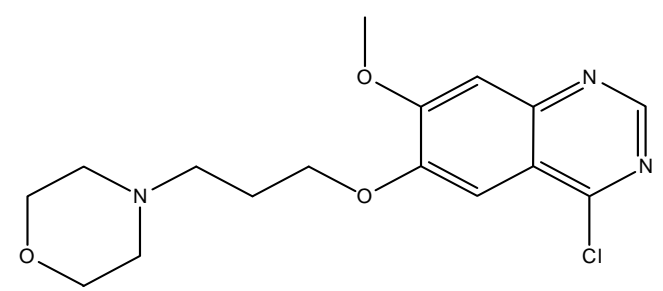

Impurity-1: 4-chloro-6-(3-morpholinopropoxy)-7-methoxyquinazoline.<smiles>CCOC(=O)c1cc(OCCCN2CCOCC2)c(OC)cc1[N+](=O)[O-]</smiles>

Impurity-2: Ethyl-4-methoxy-6-nitro-3-[3-(4-morpholinyl) propoxy] benzoate.

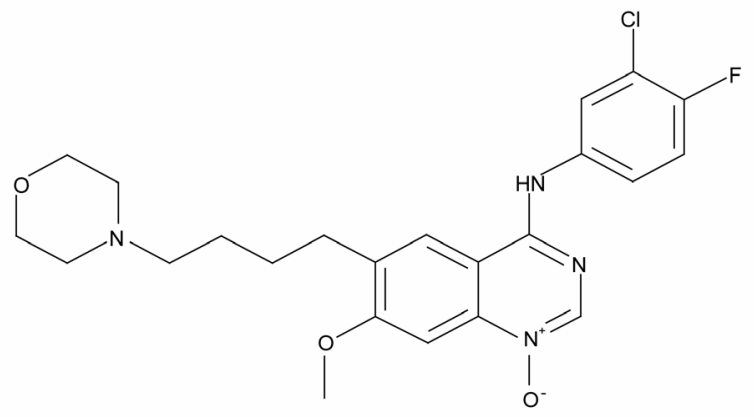

N-Oxide impurity: N-(3-chloro-4-fluoro-phenyl)-7-methoxy-6-(3-mormorpholin-4-ylpropoxy) quinazolin-4-amine $\mathrm{N}$ oxide.

Figure 1. Chemical structures and labels of gefitinib and its impurities.

variety of ICH recommended test conditions [7-9].

\section{Experimental Design}

\subsection{Chemicals}

Samples of gefitinib and its impurities are received from Hetero Laboratories Ltd, a research foundation of the firm Hetero drugs Ltd, Hyderabad, India. HPLC grade ammonium acetate and acetonitrile are purchased from Merck, Darmstadt, Germany. Chromatographic reagent grade hydrogen peroxide, hydrochloric acid, sodium hydroxides are purchased from Merck, Darmstadt, Germany. High purity water is prepared by using Milli-Q water purification system. All samples and impurities used in this study are of having greater than $99.8 \%$ purity.

\subsection{Procedure}

\subsubsection{Equipment}

The RRLC system, used for method development and method validation is Agilent 1200 RRLC. The output signal is monitored and processed using chemstation software on Pentium computer (Digital equipment Co). RRLC is equipped with Binary gradient pump, Auto Sampler, thermostatted column compartment, variable wavelength detector, Auto sampler thermostatted (G 1330B), Computer with windows based chemstation software version B.03.02. Photo stability studies are carried out in a photo stability chamber equipped with Zenon arc lamp (Atlas Suntest CPS+;). Thermal stability studies are carried out in a dry hot air oven (Cintex precision hot air oven).

\subsubsection{Chromatographic Conditions}

The chromatographic column used is Agilent make XDB-C18, $50 \times 4.6 \mathrm{~mm}$ with $1.8 \mu \mathrm{m}$ particles. The mobile phase is prepared by mixing buffer and acetonitrile in the ratio of 40:60 $(\mathrm{v} / \mathrm{v})$. Buffer is prepared by dissolving $0.77 \mathrm{~g}$ of ammonium acetate dissolved in $1000 \mathrm{~mL}$ of water. The flow rate of the mobile phase is maintained $0.5 \mathrm{~mL} \cdot \mathrm{min}^{-1}$. The column temperature is maintained at $40^{\circ} \mathrm{C}$ and the detection is monitored at a wavelength of $250 \mathrm{~nm}$. The injection volume is $4 \mu \mathrm{L}$. Diluent is a mixture of buffer and acetonitrile in the ratio of 60:40 $(\mathrm{v} / \mathrm{v})$.

\subsubsection{Preparation of Solutions}

Stock solution of gefitinib $\left(0.1 \mathrm{mg} \cdot \mathrm{mL}^{-1}\right)$ is prepared by dissolving appropriate amount in the diluent.Working solutions of $1.5 \mu \mathrm{g} \cdot \mathrm{mL}^{-1}$ were prepared from above stock solution for related compounds determination and assay determination, respectively by dissolving in diluents. Impurities stock solution (mixture of gefitinib, impurity-1 \& impurity-2) at a concentration of $0.1 \mathrm{mg} \cdot \mathrm{mL}^{-1}$ is also prepared in diluent.

\subsection{Method Development and Optimization}

Impurities and gefitinib solutions are prepared in diluent at a concentration of $100 \mathrm{ppm}$ and scanned in UV-visible 

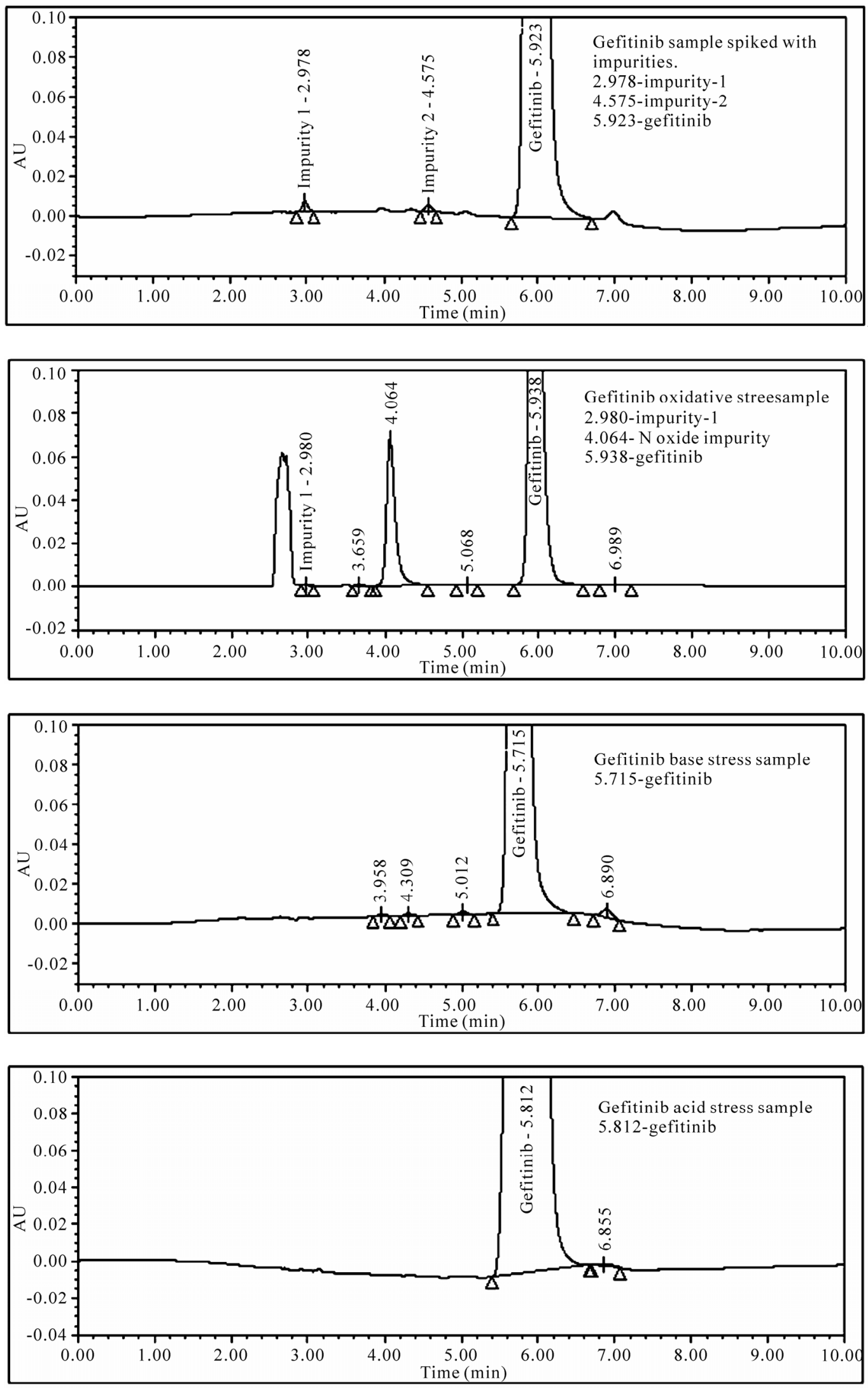

Figure 2. Typical chromatograms of specification level impurities spiking in $100 \%$ sample and stress samples. 
spectrometer; the two impurities and gefitinib are having UV maxima at $250 \mathrm{~nm}$ which is selected for method development purpose. To achieve separation of gefitinib from its impurities and degradation products chromatographic method is developed using various stationary phases like C8 and C18, different mobile phases containing buffers like phosphate and acetate and using organic modifiers like acetonitrile and methanol in the mobile phase across the $\mathrm{pH} 2$ to 8 . Mobile phase of ammonium acetate and acetonitrile $(60: 40, v / v)$ is selected for initial trial on a BEH C18, $50 \times 4.6 \mathrm{~mm}$ with $1.8 \mu \mathrm{m}$ particles and flow rate at $1.0 \mathrm{~mL} \cdot \mathrm{min}^{-1}$. Spike sample analysis revealed that principal peak retention time is late and impurities 1 and 2 are not resolved properly. Similar results are obtained with Agilent XDB, C8 $50 \times 4.6 \mathrm{~mm}$ with $1.8 \mu \mathrm{m}$ particles, with the $250 \mathrm{~mm}$ the tailing factor is observed more than 3 (broad shape).

To increase the resolution between each component Agilent XDB C18 column with the dimensions $50 \times 4.6$ with $1.8 \mu \mathrm{m}$ particles is selected. After several other trials satisfactory results (retention time of gefitinib is $\sim 5.935 \mathrm{~min}$ and the resolution between all the impurities is $>5.0$ ) are obtained. In the optimized conditions gefitinib, impurity-1, impurity-2 are well separated with a resolution greater than 5.0 and the typical retention times of gefitinib, impurity-1 and impurity-2, are about 5.923, 2.978 and 4.575 min respectively meeting the chromatographic system suitability requirements. In XDB C18 column with the dimensions $50 \times 4.6 \mathrm{~mm}$ with $1.8 \mu \mathrm{m}$ particles the components are separated with resolution above 5. In the optimized conditions tailing factor for all the components is observed between 0.8-1.5. Theorical plates are observed above 8000 .

\subsection{Analytical Method Validation}

The developed chromatographic method is validated for specificity and stress studies, sensitivity, linearity \& range, precision, accuracy, robustness and system suitability [10-15].

\subsubsection{Specificity and Stress Studies}

Specificity is the ability of the method to measure the analyte response in the presence of its potential impurities. The specificity [10-11] of the developed LC method for gefitinib is determined in the presence of its impurities namely impurity- 1 and impurity- 2 at a concentration of $1.5 \mu \mathrm{g} \cdot \mathrm{mL}^{-1}$ and degradants. The stress conditions employed for degradation study includes photolytic (carried out as per ICH Q1B), thermal $\left(100^{\circ} \mathrm{C}\right)$, acid hydrolysis $(1 \mathrm{M} \mathrm{HCl})$, base hydrolysis $(2 \mathrm{M} \mathrm{NaoH})$ and oxidation $\left(6 \% \mathrm{H}_{2} \mathrm{O}_{2}\right)$. All stressed samples of gefitinib are analysed for an extended run time of 10 min to check the late eluting degradants. Assays are carried out for stress samples against qualified reference standard and the mass balance $(\%$ assay $+\%$ of impurities $+\%$ of degradation products) is calculated for all the samples.

\subsubsection{Precision}

The precision of the related substance method is checked by injecting six individual preparations of $\left(0.5 \mathrm{mg} \cdot \mathrm{mL}^{-1}\right)$ gefitinib spiked with $0.03 \%$ each impurity. The $\%$ RSD for percentage of each impurity is calculated.

The intermediate precision (ruggedness) of the method is evaluated by different analyst using different column, different day and different analyst in the same laboratory. Precision is determined through repeatability (intra-day) and intermediate (inter-day) precision and calculated the $\%$ RSD for the area of each component.

\subsubsection{Sensitivity}

Sensitivity is determined by establishing the limit of detection (LOD) and limit of quantification (LOQ) for gefitinib, impurity- 1 and impurity- 2 estimated based on signal-to-noise ratio method, by injecting a series of dilute solutions with known concentration. The precision study is also carried out at the LOQ level by injecting six individual preparations of impurity- 1 and impurity- 2 and calculated the $\%$ RSD for the areas of each component.

\subsubsection{Linearity and Range}

Linearity test solutions from LOQ to $150 \%$ with respect to test concentration are prepared by diluting the impurity stock solution to the required concentrations. For assay method test solutions from $50 \%$ to $150 \%$ with respect to test concentration are prepared by diluting the stock solution to the required concentrations. The correlation coefficient, slope and Y-intercept of the calibration curve are calculated for the both related substances and assay methods.

\subsubsection{Accuracy}

A known amount of the impurity stock solutions are spiked to the previously analysed samples at LOQ $(100 \%$ sample $+0.03 \%$ impurities $), 100(100 \%$ sample $+0.15 \%$ impurities) and $150 \%$ (100\% sample $+0.225 \%$ impurities) of the analyte concentration $\left(0.5 \mathrm{mg} \cdot \mathrm{mL}^{-1}\right)$. The percentage of recoveries for impurity-1, impurity- 2 are calculated. A known amount of gefitinib stock solution spiked to the sucrose at $50 \%, 100 \%$ and $150 \%$ of the analyte concentration $\left(0.5 \mathrm{mg} \cdot \mathrm{mL}^{-1}\right)$. Each concentration level is prepared for three times. The percentage of recoveries is calculated.

\subsubsection{Robustness}

To determine the robustness of the developed method, experimental conditions are deliberately changed and the 
resolution between each component is evaluated. The flow rate of the mobile phase is $0.5 \mathrm{~mL} \cdot \mathrm{min}^{-1}$. To study the effect of flow rate on the resolution, 0.03 units changed i.e. 0.3 and $0.7 \mathrm{~mL} \cdot \mathrm{min}^{-1}$. The effect of column temperature on resolution is studied at $35^{\circ} \mathrm{C}$ and $45^{\circ} \mathrm{C}$ instead of $40^{\circ} \mathrm{C}$. In the all above varied conditions, the components of the mobile phase are held constant.

\subsubsection{Solution Stability and Mobile Phase Stability}

The solution stability of gefitinib and its related impurities are carried out by leaving spiked sample solution in tightly capped volumetric flask at room temperature for $48 \mathrm{~h}$. Impurity content is determined for every $6 \mathrm{~h}$ interval up to the study period. Mobile phase stability is also carried out for $48 \mathrm{~h}$ by injecting the freshly prepared sample solutions for every $6 \mathrm{~h}$ interval. Impurity content is checked in the test solutions. Mobile phase prepared is kept constant during the study period.

\section{Results and Discussion}

\subsection{Specificity and Stress Studies}

Stress studies on gefitinib under different stress conditions suggested the following degradation behavior. Table 2.

\subsubsection{Degradation in Acid Stress Condition}

Gefitinib is exposed for degradation with time in $1 \mathrm{M}$ $\mathrm{HCl}$ upon heating for $6 \mathrm{~h}$ and no degradation is observed.

\subsubsection{Degradation in Base Stress Condition}

Gefitinib is exposed for degradation with time in $2 \mathrm{M}$ $\mathrm{NaOH}$ upon heating for $6 \mathrm{~h}$ and no degradation is observed.

\subsubsection{Degradation in Peroxide Stress Condition}

Gefitinib is gradually undergone degradation with time in $6 \% \mathrm{H}_{2} \mathrm{O}_{2}$ upon heating for $2 \mathrm{~h}$ and prominent degradation is observed as gefitinib N-Oxide. Gefitinib is sensitive to oxidative condition and is degraded into unknown impurities by oxidation using $6 \% \mathrm{H}_{2} \mathrm{O}_{2}$. Gefitinib has shown significant sensitivity towards oxidative treatment. The drug gradually undergone degradation with time and degraded into unknown $(\sim 14.0 \%)$. The positive electro spray ionization (ESI) spectrum of the RT $\sim 20.0 \mathrm{~min}$ impurity showed peaks at $\mathrm{m} / \mathrm{z} 463.11(\mathrm{M}+1)$ which indicate the N-Oxide of gefitinib. The chemical name of the degradant at RT $\sim 20.0$ min could be N-(3-chloro-4fluoro-phenyl)-7-methoxy-6-(3-morpholin-4-ylpropoxy) quinazolin-4-amine $\mathrm{N}$ oxide (Figure 4).

\subsubsection{Degradation in Neutral Water Stress Condition} Gefitinib is exposed water heating for 8 hours at $80^{\circ} \mathrm{C}$, no degradation is observed.

\subsubsection{Photolytic Stress Condition}

Gefitinib is exposed to light for an overall illumination of 1.2 million Klux hours and an integrated near ultraviolet energy of 200-watt hours/square meter (w/mhr) (in photo stability chamber), no degradation is observed.

Table 1. System suitability report.

\begin{tabular}{cccc}
\hline Compound & $\begin{array}{c}\text { USP resolution } \\
\left(\mathrm{R}_{\mathrm{S}}\right)\end{array}$ & $\begin{array}{c}\text { USP tailing } \\
\text { factor }\end{array}$ & $\begin{array}{c}\text { No. of theoretical } \\
\text { plates (USP } \\
\text { tangent method) }\end{array}$ \\
\hline Impurity-1 & --- & 1.2 & 9998 \\
Impurity-2 & 10.842 & 1.4 & 12115 \\
Gefitinib & 6.440 & 1.2 & 9099 \\
\hline
\end{tabular}

Table 2. Summary of forced degradation results.

\begin{tabular}{cccccc}
\hline Stress condition & \%Total impurities & Study time & $\begin{array}{c}\text { \% Assay of } \\
\text { active substance }\end{array}$ & $\begin{array}{c}\text { Mass balance } \\
\text { \% assay }+\% \text { impurities }+ \\
\% \text { degradation products })\end{array}$ & Remarks \\
\hline $\begin{array}{c}\text { Acid hydrolysis } \\
(1 \mathrm{M} \mathrm{HCI})\end{array}$ & $0.15 \%$ & $6 \mathrm{~h}$ & 99.4 & 99.6 & $\begin{array}{c}\text { No degradation products were } \\
\text { formed }\end{array}$ \\
$\begin{array}{c}\text { Base hydrolysis } \\
(2 \mathrm{M} \mathrm{NaOH})\end{array}$ & $0.15 \%$ & $6 \mathrm{~h}$ & 99.4 & 99.6 & $\begin{array}{c}\text { No degradation product is } \\
\text { formed }\end{array}$ \\
$\begin{array}{c}\text { Oxidation } \\
\left(15 \% \mathrm{H}_{2} \mathrm{O}_{2}\right)\end{array}$ & $14.0 \%$ & $2 \mathrm{~h}$ & 86.2 & $\begin{array}{c}\text { One major degradation ob- } \\
\text { served and identified as } \\
\text { N-oxide impurity of gefitnib } \\
\text { by LC-MS }\end{array}$ \\
$\begin{array}{c}\text { Thermal }\left(100^{\circ} \mathrm{C}\right) \\
\text { Light (photolytic } \\
\text { degradation) }\end{array}$ & $0.16 \%$ & $168 \mathrm{~h}$ & 99.5 & 99.7 & $\begin{array}{c}\text { No degradation products } \\
\text { formed }\end{array}$ \\
\hline
\end{tabular}




\subsubsection{Thermal Stress Condition}

Gefitinib exposed to dry heat at $100^{\circ} \mathrm{C}$ for 168 hours, no degradation is observed. The mass balance of stressed samples is close to $99.5 \%$.

The assay of gefitinib is unaffected in the presence of two impurities and its degradants confirm the stability indicating power of the developed method.

\subsection{Method Validation}

\subsubsection{Precision}

The $\%$ RSD of area of gefitinib, impurity-1 and impurity- 2 and $\%$ RSD of area $\%$ of each impurity in precision study are less than 5.0 confirming the good precision of the developed analytical method. The \%RSD obtained in intermediate precision study for gefitinib, impurity-1, impurity-2 are less than 5.0, confirming the intermediate precision of the method.

\subsubsection{Sensitivity}

The limit of detection of gefitinib, impurity- 1 and impurity-2 is 0.01 and $0.01 \%$ (of analyte concentration, i.e. $0.50 \mathrm{mg} \cdot \mathrm{mL}^{-1}$ ) respectively for $4 \mu \mathrm{L}$ injection volume. The limit of quantification of gefitinib, impurity-1 and impurity-2 is 0.03 and $0.03 \%$ (of analyte concentration, i.e. $0.50 \mathrm{mg} \cdot \mathrm{mL}^{-1}$ ) respectively for $4 \mu \mathrm{L}$ injection volume. The $\%$ RSD for area of impurity- 1 and impurity- 2 are less than 5.0 for precision at LOQ level.
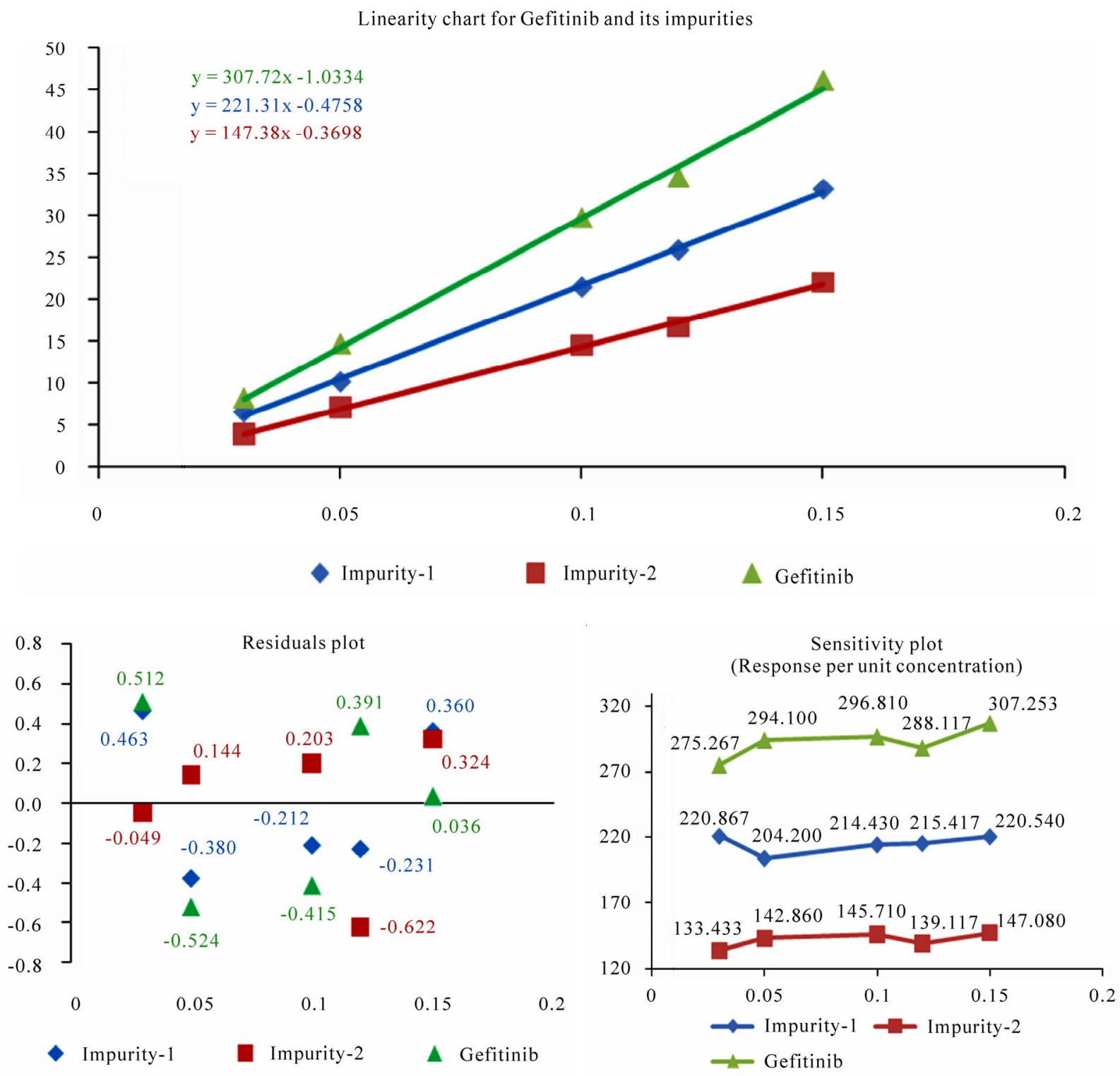

Figure 3. Linearity chart for gefitinib and its impurities. 


\subsubsection{Linearity and Range}

Calibration curve obtained by the least square regression analysis between peak area and concentration exhibited linear relationship with a correlation coefficient of 0.998 over the ranges tested. Linear calibration plot for related substance method is obtained over the ranges tested, i.e. LOQ to $0.225 \%$ for Impurity-1, Impurity- 2 and LOQ to $0.15 \%$ for gefitinib. The correlation coefficient obtained is greater than 0.998 for the two impurities and gefitinib.
\% Y-intercept is below 5.0 as per acceptable validation practices. The result shows an excellent correlation existed between the peak area and concentration of gefitinib and impurities. Linear calibration plot for assay determination method is obtained over the calibration ranges tested, i.e. $50 \%$ to $150 \%$ for gefitinib and the correlation coefficient is found more than 0.999 . The results show an excellent correlation existed between the peak area and concentration of gefitinib in assay determination

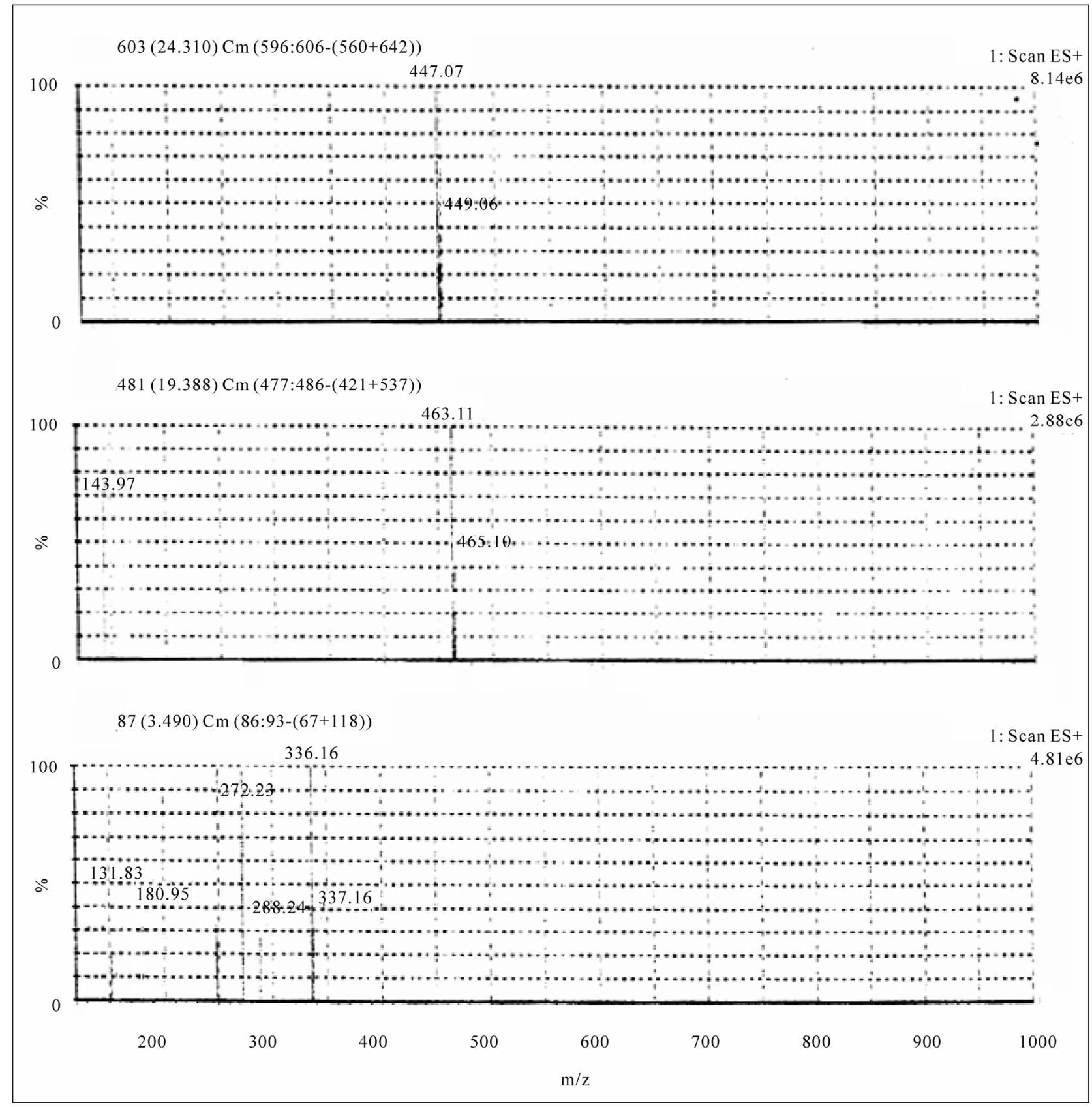

Figure 4. Mass spectrum of oxidation degradation impurity (Gefitinib N-oxide impurity) N-(3-chloro-4-fluoro-phenyl)-7methoxy-6-(3-morpholin-4-ylpropoxy) quinazolin-4-amine $\mathrm{N}$ oxide. 
Table 3. Linearity, regression results for impurities and gefitinib.

\begin{tabular}{cccc}
\hline Parameter & Impurity-1 & Impurity-2 & Gefitinib \\
\hline Trend line equation & $\mathrm{Y}=221.31 \mathrm{x}-4758$ & $\mathrm{Y}=147.38 \mathrm{x}-0.3698$ & $\mathrm{Y}=307.72 \mathrm{x}-1.0334$ \\
Range & $0.03 \%-0.15 \%$ & $0.03 \%-0.15 \%$ & $0.03 \%-0.15 \%$ \\
Regression Coefficient & 0.999 & 0.998 & 0.998 \\
Slope & 221.31 & 147.38 & 307.72 \\
Intercept & -0.4758 & -0.3698 & -1.0334 \\
\%Intercept with respect to 100\% \\
conc. response
\end{tabular}

method (Figure 4, Table 3).

\subsubsection{Accuracy}

The percentage recovery of impurity- 1 and impurity- 2 in bulk drug samples ranged from 97.35-101.91. HPLC chromatogram of Gefitinib bulk drug sample spiked with the two impurities is shown in Figure 2 (Table 4).

\subsubsection{Robustness}

Analysis results for deliberately changed chromatographic conditions (flow rate and column temperature) revealed that the resolution between closely eluting impurities, namely gefitinib and impurity-2 is greater than 5.0, illustrating the robustness of the method. Repeatability and reproducibility results also within the \% RSD of 5.0.

\subsubsection{Solution Stability and Mobile Phase Stability}

The \%RSD of assay of gefitinib during solution stability and mobile phase stability experiments is within 1.0. No significant changes are observed in the content of impurity-1 and impurity-2 during solution stability and mobile phase stability experiments. The solution stability and mobile phase stability experiments data confirms that sample solutions and mobile phase used related substance determination are stable up to the study period of $48 \mathrm{~h}$.

Analysis is performed for different samples of gefitinib $(n=3)$. The two impurities in these samples are less than $0.1 \%$.

Table 4. Results of accuracy study for related compounds.

\begin{tabular}{ccc}
\hline $\begin{array}{c}\text { Amount of impurity } \\
\text { added ( } \begin{array}{c}\boldsymbol{\mu} \text { g) to the } \mathbf{1 0 0} \% \\
\text { sample (n) }\end{array}\end{array}$ & $\begin{array}{c}\text { \% Recovery } \\
\text { of impurity-1 }\end{array}$ & $\begin{array}{c}\text { \% Recovery of } \\
\text { impurity-2 }\end{array}$ \\
\hline 0.03 & 99.80 & 101.91 \\
0.10 & 99.08 & 101.77 \\
0.15 & 101.23 & 97.35 \\
\hline
\end{tabular}

$n=3$, number of determinations.

\section{Conclusion}

The degradation pathway of gefitinib is established as per ICH recommendations. The proposed method is validated as per ICH requirements. The isocratic RRLC method developed can be used for stress studies and for quantitative determination of related substance and assay of gefitinib. The developed method is stability indicative and can be employed in routine analysis of gefitinib production samples and also to analyze stability samples.

\section{Acknowledgements}

The authors grateful to the management of Hetero labs limited for the extensive support in achieving this work.

\section{References}

[1] D. H. Lee, J. Y. Han, H. T. Kim and J. S. Lee, “Gefitinib is of More Benefit in Chemotherapy-Naive Patients with Good Performance Status and Adenocarcinoma Histology: Retrospective Analysis of 575 Korean Patients," Lung Cancer, Vol. 53, No. 3, 2006, pp. 339-345. doi:10.1016/j.lungcan.2006.05.015

[2] K. Kataoka, H. Taniguchi, Y. Hasegawa, Y. Kondoh, T. Kimura, O. Nishiyama, K. Imaizumi, T. Kawabe, H. Kume and K. Shimokata, "Interstitial Lung Disease Associated with Gefitinib," Respiratory Medicine, Vol. 100, No. 4, 2006, pp. 698-704. doi:10.1016/j.rmed.2005.07.015

[3] Y. M. Yin, Y. T. Geng, X. D. Li, X. L. Hu, X. F. Chen, W. Li and Y. Q. Shu, "Efficacy of Gefitinib as a First-Line Single Agent Treatment in Patients with Advanced Non Small Lung Cancer," Journal of Nanjing Medical University, Vol. 23, No. 6, 2009, pp. 392-397. doi:10.1016/S1007-4376(09)60088-5

[4] J. Araki, I. Okamoto, R. Suto, Y. Ichikawa and J. Sasaki, "Efficacy of the Tyrosine Kinase Inhibitor Gefitinib in a Patient with Metastatic Small Cell Lung Cancer," Lung 
Cancer, Vol. 48, No. 1, 2005, pp. 141-144. doi:10.1016/j.lungcan.2004.10.012

[5] V. K. Kumar, N. A. Raju, S. Begum, J. S. Rao and T. Satyanarayana, "The Estimation of Gefitinib in Tablet Dosage Forms by RP-HPLC," Research Journal of Pharmacy and Technology, Vol. 2, No. 2, 2009, pp. 341-343.

[6] G. Guetens, H. Prenen, G. De Boeck, W. Van Dongen, E. Esmans, F. Lemiere, A. Van Oosterome, P. Schoffski and E. De Bruijn, "Sensitive and Specific Quantification of the Anticancer Agent ZD1839 (Iressa) in Plasma by On-Column Focusing Capillary Liquid Chromatography-Tandem Mass Spectrometry," Journal of Chromatography A, Vol. 1 No. 2-5, 2005, p.1082.

[7] "Stability Testing of New Drug Substances and Products," ICH, Q1A (R2), 2005.

[8] "Photo Stability Testing of New Drug Substances and Products", ICH, Q1B, 2005.

[9] "Validation of Analytical Procedures: Text and Methodology”, ICH Q2 (R1), 2005

[10] S. W. Baertschi, K. Alsante and R. A. Reed, "Pharmaceutical Stress Testing: Predicting Drug Degradation," Drugs and the Pharmaceutical Sciences, Informa Healthcare, 2005.
[11] M. Bakshi and S. Singh, "Development of Validated Stability Indicating Assay Methods-Critical Review," Journal of Pharmaceutical and Biomedical Analysis, Vol. 28, 2002, pp. 1011-1040. doi:10.1016/S0731-7085(02)00047-X

[12] "Guidance for Industry: Analytical Procedures and Methods Validation," US FDA, 2000.

[13] "Validation of Compendial Methods," The United States Pharmacopeia Convention, 12601 Twinbrook Parkway, Rockville, MD, 20852, ch<1225>, 2009, pp. 2622-2625.

[14] M. E. Swartz and I. S. Krull, "Developing and Validating Stability Indicating Methods," Pharmaceutical Technology, Vol. 23, No. 6, 2006, p. 46.

[15] J. Ermer and J. H. M. Miller, "Method Validation in Pharmaceutical Analysis: A Guide to Best Practice," Wiley-VCH, GmbH \& Co. KGaA, Weinheim, 2005, pp. 205-208.

[16] D. M. Bliesner, "Validating Chromatographic Methods: A Practical Guide," Wiley-VCH, GmbH \& Co. KGaA, Weinheim, 2006.

[17] J. T. Carstensen and C. T. Rhodes, "Drug Stability Principles and Practices," 3rd Edition, Marcel Dekker, New York, 2000. 